acid or salicyl acetic acid. It is a fine white crystalline powder, sparingly soluble in water, and is given in suspension, in cachets or in compressed form. It has been used as a substitute for salicylic acid and the salicylates. My experience with this remedy is comparatively limited and I do not desire to come into conflict with those of more extended experience. Having tried it in several cases of acute rheumatism I have not been convinced that for this purpose it possesses any advantage over salicylic acid or the salicylates and have returned to their employment. In some patients dyspeptic symptoms followed its use in addition to very profuse perspiration ; the former symptoms have sometimes been accompanied by some diarrhœa which has sufficed to produce a strong disinclination to continue the use of this remedy. The cases in which I have found it to be of most service are those of severe headache occurring as the result of overwork or over-anxiety, especially when there are evidences of a gouty diathesis. Under these conditions I have frequently found that a dose of ten grains before going to bed has produced free perspiration, which has been followed by relief of pain and by refreshing sleep. I have also used aspirin for migraine but although it has occasionally been of service it has often failed. From the perspiration it induces I never give aspirin unless the patient is on the point of going to bed.

Mesotan.-This is a yellow liquid, almost odourless, or with a slight aromatic odour. It is the methoxy-methyl ester of salicylic acid. It is insoluble in water, soluble in alcohol, and readily miscible in olive oil. It is readily absorbed by the skin, salicylic acid being found in the urine shortly after its local application. It is stated to have been used with excellent results in all forms of rheumatic and gouty affections. In my hospital work mesotan mixed with one or two parts of olive oil has appeared to afford relief in the after-treatment of acute rheumatism. It has not been of any service during the continuance of the fever, but after the fall of temperature many of my patients have said that they have quickly lost pain and stiffness in their joints with the local application of mesotan. While fully aware of the possible fallacy of such observations I have been struck by their unanimity, which can scarcely be a coincidence. In some cases of gonorrhoal rheumatism mesotan has not given the slightest relief and in one such case well-marked local irritation followed its use. At the time I was inclined to think the patient had been too energetic in his desire to rub in a quantity, but $I$ have since seen it stated that this result has been observed by others, when after the application of mesotan the limb has been surrounded with an impervious covering, while another suggestion is that the irritation is due to admixture with water and decomposition of the mesotan. Both points are noteworthy as they supply hints for directions. Mesotan should be free from water; it should not be used without dilution with olive oil, it should be applied with a brush without friction, and the surface should not be subsequently covered with thick flannel, cotton-wool, or protective tissue.

Ovoferrin or iron vitellin.-Some present may remember that in a paper on the Treatment of Some Forms of Anæmia ${ }^{2}$ I recently gave the results of some observations with this substance. I may, however, state here that this substance is produced by heating together under pressure solutions of serum albumin and iron tartrate ; the resulting precipitate is freed from impurities and supplied in solution with just enough alcohol to check decomposition. The dose of this solution is from two fluid drachms in an ounce of water three times a day. In this paper, after mentioning the general objections to many of the official forms of iron and its compounds and the various efforts to obtain a true organic iron preparation, I gave details of some investigations which had been conducted in my wards with ovoferrin. The general principle was first to estimate the percentage of hæmoglobin in the blood and to make subsequent estimations at intervals of a week during the administration of the new remedy. For the details I would venture to refer you to my paper but the conclusions I would like to summarise here. The hæmoglobin in most cases increased markedly within a short time and synchronously there was great improvement in digestive power and in general well-being. The most satisfactory features were the readiness with which the remedy was taken, owing to its pleasing appearance and its absence of taste, the cheering rapidity of the improvement,

2 The Practitioner, August, 1904. and the total absence of any digestive disturbance or constipation as a consequence.

$\hat{\mathrm{I}}$ am tempted to refer once more to this subject since further experience has not weakened the views then expressed and I am able to say more of one of the cases which did not then afford full satisfaction. In a case of pernicious anæmia we watched a rapid reduction of hæmoglobin with considerable anxiety and finally gave liquor arsenicalis in addition to the ovoferrin. When my paper was written the hæmoglobin had risen from 25 to 30 per cent. and in spite of this small proportion it was noted that the aspect had improved very materially. The hæmoglobin increased from this date (June 20th) until by July 19th it had reached 64 per cent. ; at this time 15 minims of liquor arsenicalis were being given three times a day. This dose produced keratosis of the palms of the hands and some smarting of the eyelids, together with loss of appetite and abdominal pain. The arsenic was accordingly stopped and it is interesting to note that although there was a subsequent slight fall in the percentage of hæmoglobin the general condition remained satisfactory.

And now for the word of warning connected with this preparation. Do not forget that this organic preparation of iron only contains sufficient alcohol to arrest decomposition when undiluted and that it should therefore only be mixed with water at the time when it is taken; neglect of this simple precaution is likely to produce disastrous results.

In conclusion I would like to repeat that I am well aware of the numerous sources of possible fallacy inseparable from any attempt to determine the value of remedies from clinical observations. These risks are necessarily greater when investigating remedies used for the relief of pain. I have endeavoured not to fall into this pitfall and have used guarded terms in such circumstances. On the other hand, there can be few such risks when clinical reports can be supplemented by definite changes like the amount of pus in the urine or the percentage of hæmoglobin in the blood.

Harley-street, W,

\section{HÆMORRHAGIC TYPHOID FEVER.}

By DAVID BLAIR, M.A., M.D. GLASG.,

ASSISTANT MEDICAL OFFICER AT THE COUNTY ASYLUM, LANCASTER.

SEVeral cases and articles bearing on this distinctly rare condition have appeared in the columns of THE LANCET. I refer especially to two contributions by the late Dr. T. J. Maclagan on the Relation of the Bowel Lesion of Typhoid Fever to the General Symptoms of the Disease, ${ }^{1}$ a joint article by Dr. A. G. Nicholls and Mr. G. Everett Learmouth of McGill University on the Hæmorrhagic Diathesis in Typhoid Fever and its Relation to Purpuric Conditions in General ${ }^{2}$ and the description of a case at St. George's Hospital, under the care of Dr. W. Ewart. ${ }^{3}$ In connexion with these the following case and suggestions may be of some interest.

A woman, aged 24 years, was admitted to the asylum on July 12th, 1895. She had earned her living as a charwoman. Since the age of 14 years she had been subject to epileptic fits and had two or three per diem. She was somewhat addicted to drink. When admitted she complained of having suffered from various mysterious maladies and said that she had had a tumour in the side for which she had undergone an operation. She was violent, excited, and had delusions of persecution. Physically she was well nourished but very anæmic. During the whole of her year's sojourn at the asylum she was hypochondriacal, fretful, quarrelsome, and hard to manage. She complained of a pain in her left side, of which there was no physical sign, and insisted on wearing a plaster and bandage over it. Now and again, especially when one happened to be looking, she would gasp, catch her breath and throat and appear to be troubled with something of the nature of globus hystericus. Despite her many drawbacks she was a useful worker in the wards.

On July 2nd, 1896, her bodily health was reported to the

1 The LaNCET, Dec. 8th, 1900, p. 1639, and Jan. 12th, 1901, p. 93. 2 THE LANCET, Feb. 2nd, 1901, p. 305. 3 THE LANCET, July 6th, 1901, p. 25. 
Commissioners in Lunacy as good. She took her food well and continued her work until the 16 th. On that morning she took part in the usual scrubbing but later was reported not to have taken her breakfast and to be passing blood per rectum. I found her pulse-rate to be 140 , her respiration 44, and her temperature nearly $105^{\circ} \mathrm{F}$. She looked drowsy and ill and complained of pains all over the body. She was frequently purged during the day while some of the stools seemed to consist of nothing but blood. Apart from the rapidity of the heart and respiration, physical examination of the chest revealed nothing abnormal. There was no rash ana no enlargement of the spleen could be felt. On the 17 th her temperature was $105.0^{\circ}$ in the morning and $104.0^{\circ}$ in the evening. On the 18 th it was $103.0^{\circ}$ in the morning but was brought down to $101^{\circ} 6^{\circ}$ in the afternoon by sponging with tepid water and vinegar. On the 19 th it was $103.0^{\circ}$ in the morning and $104.8^{\circ}$ in the evening. On the 20th a considerable increase in the tumescence of the abdomen was noted; the urine, which had been carefully drawn off with the catheter, was found to contain blood, while petechiæ had come out on the legs and arms. At the bases of both lungs râles were now audible, bronchophony was well marked, while there were small areas of tubular breathing. On the 21st her temperature was $105.0^{\circ}$ in the morning and $104.0^{\circ}$ in the evening. On the next day there was considerable epistaxis while blood was also shed from the gums. At night the patient had one fit and was purged three times, pure blood being passed on each occasion. On the day following (i.e., July 23rd) she had six fits and died in the evening at $60^{\circ}$ 'clock; her temperature was $100.2^{\circ}$ in the morning and $103^{\circ} 6^{\circ}$ in the afternoon.

The clinical history of this case might have been presented by three well-known and distinct morbid entities : purpura hæmorrhagica, that form of ulcerative colitis known as "acute diphtheritic dysentery," and "latent typhoid fever." of these, idiopathic purpura seemed the least probable. Hæmorrhage from the bowel preceded and relatively exceeded the hæmorrhage from any other mucous membrane. And while in this affection, as in all other forms of extreme anæmia, fever may be present, yet it seems very doubtful if it ever occurs as an initial symptom. It appeared more probable that the purpura was only symptomatic and a complication of either dysentery or typhoid fever.

My late colleague, Dr. J. F. Gemmel, in his work on Dysentery, argues that there is a much closer connexion between purpura, scurvy, and dysentery than is at present recognised. Dysentery is, odaly enough, a somewhat common affection in large asylums. But all the cases which I have seen were either afebrile or became so after the first day or two. There is, however, a type of ulcerative colitis described by Osler from which it is practically impossible to differentiate this case. I refer to acute diphtheritic dysentery, in which the patient from the outset is extremely ill with high fever, great prostration, pain in the abdomen, and frequent discharges. Delirium may be early and the clinical features are practically identical with those of severe typhoid fever. Osler says that he has known this to be mistaken for typhoid fever again and again, but that the absence of enlargement of the spleen and of the rose rash ought to lead to a eorrect diagnosis. Both of these were absent in this case, while the early appearance of the blood was much more characteristic of dysentery than of typhoid fever. I was quite aware that early signs of typhoid fever were sometimes latent and that cases were recorded of the first indication of the disease being perforation of the bowel. But up to then I had never read, or even heard, of any case of typhoid fever in which hæmorrhage was the earliest clinical indication.

A post-mortem examination was allowed and the more salient appearances were as follows. There were cutaneous hæmorrhages of from the size of a shilling to that of a half-crown on the forearms and legs. The body seemed to be well nourished, but this was due to a large layer of fat. Apart from a slight general paleness due to anæmia the brain was healthy. The heart muscle was anæmic and atheroma was beginning in the aorta. The bases of both lungs were congested and there were patches of consolidation and odema of other parts. The mesenteric glands were large, soft, and reddish. The lower 18 inches of the small intestine showed extensive ulceration of Peyer's patches and several of the ulcers had penetrated right down to the peritoneal coat. The ulcers were typical of the third stage of enteric fever and they stopped abruptly at the ileo-cæcal valve. The spleen was acutely congested and weighed six and a half ounces. The kidneys were fairly healthy but they, too, weighed six and a half ounces each.

The disease, therefore, was obviously one of those extremely unusual types of typhoid fever exhibiting the hæmorrhagic diathesis. It is extremely rare. In Ouston's 6513 cases of typhoid fever there were only four and in Osler's 829 cases there was only one.

The most remarkable feature of the case I have described was the latency of the early symptoms of the disease and at the first blush we were tempted to ascribe it to the patient's abnormal mental state. Disturbed mental conditions sometimes completely mask physical disorder. Patients are occasionally brought to the asylum as cases of melancholia or mania who on being carefully examined are really found to be suffering from typhoid fever. The sensibility of the insane to physical discomfort may be both blunted and perverted and it is obvious that a patient could hardly suffer so persistently from epilepsy for 12 years without acquiring some degree of dementia. But the fact remains that typhoid fever in the insane runs, as a rule, the same course and presents precisely the same symptoms as in the sane. And one can hardly imagine any psychosis which could regulate a temperature, avert diarrhoea, or suppress a typhoid fever rash.

I think, however, a sequence of pathological conditions which would account for this clinical history is quite intelligible apart from mental phenomena. If we take it that the bacilli first entered the body by ingestion, we may regard the initial intestinal lesions as infective granulomata produced like the products of tubercle by the local action of the specific bacillus. During the period of invasion we can easily imagine the morbid action to be limited entirely to Peyer's patches and the closed follicles without any material absorption into the system of the bacilli or their spores; and so the intestinal lesions might smoulder on for some time without giving rise to any very marked bodily symptoms. When, however, the stage of ulceration was reached, with erosion of vessels, profuse hæmorrhage, and the discharge of the poison into the bowel, an absorbing surface and absorbent toxins of a vastly different character would be presented and auto-infection might rapidly take place. Nor would this absorption necessarily be limited to Eberth's bacilli and their spores. We know that in a necrotic and ulcerative condition of the bowel with sloughs partially adherent, septic and pyæmic mixed infection starting from the ulcers would most likely be superadded. Such, I think, is a very reasonable interpretation of the morbid phenomena underlying the clinical appearances.

As to treatment it was, of course, purely symptomatic. But in the last few days when absolutely nothing was retained by the stomach and rectal feeding was out of the question really good results for a time were got by feeding hypodermically with a mixture of salt solution and white of egg. Lancaster.

\section{INJURIES TO THE EYE BY PENETRATING FOREIGN BODIES AND THE RESULTS AFTER MAGNET OPERATIONS. ${ }^{1}$}

\footnotetext{
BY LESLIE BUCHANAN, M.D. GLASG.,
}

SURGEON AND PATHOLOGIST TO THE GLASGOW EYE INFIRMARY.

IT has of recent years become a matter of everyday occurrence that chips of metal are extracted from the interior of eyes into which they have penetrated as a result of an accident. That this is so is largely due to the use of electromagnets (large and small) and also to the localising power of the $x$ rays. Cases are frequently recorded in which pieces of metal have been removed from the eye, but there is a much larger percentage of such cases in which there is no record except in the journals of a hospital. Unfortunately, however, although the total number of cases in which metal penetrates into the eye is large, and the proportion of these in which the metal is successfully removed is every year becoming larger, there is nothing to show in what percentage of the latter the eye preserves

I A paper read before the Southern Medical Society, Glasgow, on 1 A paper read
Dec. 15th, 1904. 